\title{
Update in Women's Health for the General Internist
}

\author{
Judith M. E. Walsh, MD, MPH' ${ }^{7}$, Megan McNamara, MD, $M S C^{2}$, Redonda G. Miller, MD, $M B A^{3}$, and \\ Eleanor Bimla Schwarz, MD, MS
}

'UCSF Division of General Internal Medicine, UCSF Women's Health Clinical Research Center, University of California, San Francisco, CA, USA; ${ }^{2}$ Louis Stokes Cleveland Veterans Affairs Medical Center, Case Western Reserve University, Cleveland, OH, USA; ${ }^{3}$ Department of Medicine, Johns Hopkins University School of Medicine, Baltimore, MD, USA; ${ }^{4}$ Center for Research on Health Care, Departments of Medicine, Epidemiology, Obstetrics, Gynecology, and Reproductive Sciences, University of Pittsburgh, Pittsburgh, PA, USA.

J Gen Intern Med 27(2):232-7

DOI: $10.1007 / \mathrm{s} 11606-011-1877-4$

(C) Society of General Internal Medicine 2011

\section{INTRODUCTION}

This update summarizes articles and guidelines published in the last year that may impact general internists' women's health clinical practice (Table 1).

\section{METHODS}

We reviewed the contents of leading medical journals including: the New England Journal of Medicine, the Journal of the American Medical Association, Annals of Internal Medicine, Archives of Internal Medicine, British Medical Journal, Lancet, Obstetrics and Gynecology, American Journal of Obstetrics and Gynecology, Journal of General Internal Medicine, PLOS Medicine, American Journal of Public Health, Circulation, Diabetes, and Diabetes Care between March 1, 2010 and February 28, 2011. We also reviewed updates to the Cochrane database of systematic reviews, Guideline Clearinghouse, and the articles highlighted by the ACP Journal Club, Journal Watch, and Journal Watch Women's Health. Finally, we performed a MEDLINE search using the medical subject heading, "sex factors." Those abstracts rated in the top third of importance by any author were read closely and rated by all authors. A process of individual ratings and multiple discussions was then used to reach consensus about the most important articles published in the last year.

\section{ISSUES FOR REPRODUCTIVE AGED WOMEN}

Abdool Karim Q, Abdool Karim S, Frohlich J. Effectiveness and safety of tenofovir gel, an antiretroviral microbicide, for the

Received June 2, 2011

Revised July 7, 2011

Accepted August 31, 2011

Published online October 13, 2011 prevention of HIV infection in women. Science. 2010;329 (5996): 1168-74.

What Was Known? Women are disproportionately affected by the HIV epidemic, yet have few ways to protect themselves from sexually transmitted infections. Over the last 20 years, six microbicides have been studied; none provide meaningful protection against HIV infection.

What this Study Adds This double-blind, randomized, placebocontrolled trial followed 889 HIV-negative, South African women who applied a $1 \%$ tenofovir vaginal gel $12 \mathrm{~h}$ before and $12 \mathrm{~h}$ after intercourse. Over 30 months of follow-up, the gel was found to have an acceptable safety profile and reduced HIV incidence by $39 \%$.

How Should I Change my Practice? The US FDA has previously approved oral tenofovir and recently "fast tracked" the $1 \%$ gel, creating hope it may be available to our patients in 2012 .

Lukes AS, Moore KA, Muse KN, et al. Tranexamic acid treatment for heavy menstrual bleeding: a randomized controlled trial. Obstet Gynecol. 2010;116(4):865-75.

What Was Known? Tranexamic acid inhibits the activation of plasminogen, increasing clot formation. Injectable tranexamic acid was FDA approved in 1986; an oral formulation has been safely used in Europe for the last 40 years and was FDA approved in 2009. ${ }^{1}$

What this Study Adds. In this RCT ( $\mathrm{n}=196)$, women treated with $3.9 \mathrm{~g} /$ day of tranexamic acid for 5 days with each menses had significant and personally meaningful reductions in menstrual blood loss at 1 month that were consistent to 6 months. In addition, women reported decreased social and physical limitations with menses.

How Should I Change my Practice? Oral transexamic acid is a new therapeutic alternative for providing short-term relief for menorrhagia, though a prior study found a levongestrel IUD was more effective than transexamic acid in providing longterm relief. ${ }^{2}$

Foster D, Hulett D, Bradsberry M, Darney P, Policar M. Number of oral contraceptive pill packages dispensed and 
Table 1. Important Women's Health Guidelines in 2010-2011: New or Updated

\begin{tabular}{|c|c|c|}
\hline Topic & $\begin{array}{l}\text { Issuing } \\
\text { organization }\end{array}$ & Updated recommendations \\
\hline $\begin{array}{l}\text { Contraceptive } \\
\text { guidelines }\end{array}$ & $\mathrm{CDC}^{*}$ & $\begin{array}{l}\text { http://www.cdc.gov/mmwr/pdf/rr/ } \\
\text { rr59e0528.pdf } \\
\text { Now includes guidance after } \\
\text { bariatric surgery, organ } \\
\text { transplantation, and with } \\
\text { inflammatory bowel disease }\end{array}$ \\
\hline $\begin{array}{l}\text { STD treatment } \\
\text { guidelines }\end{array}$ & $\mathrm{CDC}^{*}$ & $\begin{array}{l}\text { http://www.cdc.gov/std/treatment/ } \\
\text { Beware resistant gonorrhea } \\
\text { Encourage expedited partner therapy }\end{array}$ \\
\hline $\begin{array}{l}\text { CHD } \\
\text { prevention }\end{array}$ & $\mathrm{AHA}^{\dagger}$ & $\begin{array}{l}\text { Definition of "high risk" now } \\
\text { includes women with 10-year } \\
\text { risk of CHD of } \geq 10 \% \text { (as opposed } \\
\text { to previous risk of } 20 \% \text { ) } \\
\text { Definition of "at risk" broadened } \\
\text { to include evidence of subclinical } \\
\text { atherosclerosis (e.g., carotid } \\
\text { plaque), collagen vascular } \\
\text { disease, preeclampsia, } \\
\text { gestational DM, and HTN in } \\
\text { pregnancy } \\
\text { More stringent physical activity and } \\
\text { diet recommendations }\end{array}$ \\
\hline $\begin{array}{l}\text { Hormone } \\
\text { therapy }\end{array}$ & NAMS ${ }^{\ddagger}$ & $\begin{array}{l}\text { No increased risk of CHD if } \\
\text { combined hormone therapy is } \\
\text { initiated in women aged 50-59 or } \\
\text { within } 10 \text { years of menopause } \\
\text { Breast cancer risk seems to be } \\
\text { greater if combined hormone } \\
\text { therapy is initiated within } 5 \text { years } \\
\text { of menopause } \\
\text { Hot flashes equally likely to recur } \\
\text { if hormone therapy is tapered vs. } \\
\text { discontinued abruptly } \\
\text { Consider DEXA scanning after } \\
\text { hormone therapy discontinuation } \\
\text { in women with prolonged use }\end{array}$ \\
\hline $\begin{array}{l}\text { Osteoporosis } \\
\text { screening }\end{array}$ & USPSTF $^{\S}$ & $\begin{array}{l}\text { Screen women aged } 65 \text { and older } \\
\text { Screen women whose fracture risk } \\
\text { is equal to or greater than a } \\
65 \text {-year-old white woman who } \\
\text { has no additional risk factors }\end{array}$ \\
\hline Vitamin D & $\begin{array}{l}\text { Institute of } \\
\text { Medicine }\end{array}$ & $\begin{array}{l}\text { RDA } 600 \text { IU for women aged } 9-70 \\
\text { RDA } 800 \text { IU for women over age } 70 \\
\text { Upper limit } 4,000 \text { IU per day } \\
25-O H \text { Vitamin D level of } 20 \mathrm{ng} / \mathrm{ml} \\
\text { is the goal }\end{array}$ \\
\hline
\end{tabular}

${ }^{*}$ Centers for Disease Control and Prevention

${ }^{\dagger}$ American Heart Association

${ }^{\ddagger}$ North American Menopause Society

${ }^{\S}$ United States Preventive Services Task Force

subsequent unintended pregnancies. Obstet Gynecol. 2011;117 (3):566-72.

What Was Known? Oral contraceptive pills (OCPs) are the most commonly used form of reversible contraception in the $\mathrm{US},{ }^{3}$ and receiving a year's worth of pills upon initiating OCP use does not reduce preventive services such as Pap or chalmydia testing. ${ }^{4}$

What this Study Adds. Women who were given 12 packs of OCPs were less likely to experience an unplanned pregnancy $(\mathrm{OR}=0.70$, 95\% CI 0.57-0.87) or abortion (OR=0.54, 95\% CI 0.32-0.93) than those given 3 or less, even after controlling for age, race/ethnicity, and prior pill use.
How Should I Change my Practice? Provide a year's worth of pills to women interested in using an OCP regardless of other plans to provide preventive services.

Munk-Olsen T, Laursen T, Pedersen C, et al. Induced firsttrimester abortion and risk of mental disorder. NEJM. 2011;364 (4):332-9.

What Was Known? First trimester induced abortion is one of the most commonly US performed surgical procedures. ${ }^{5}$

What this study adds: In this study from multiple Danish registries, the investigators found that first trimester abortion did not affect rates of psychiatric contact $(\mathrm{p}=0.19)$ in the 9 months before or 12 months after the procedure $(n=84,620)$. However, rates of psychiatric contact were increased after childbirth $(\mathrm{p}<0.001)$ for 6 to 9 months; rates of psychiatric contact for affective disorder were highest in the first month postpartum ( $R R=3.79$, 95\% CI 2.86-5.02), but remained elevated 7-9 months postpartum $(\mathrm{RR}=1.69,1.31-2.17)$. Similarly, rates of psychiatric contact for neurotic, stressrelated, or somatoform disorders were highest 1 month postpartum and remained elevated for 7-9 months postpartum (RR=1.33 (1.11-1.60).

How should I change my practice? Women can be reassured that first trimester abortion does not increase the risk of mental disorder. Routine screening for postpartum mental disorder may be useful.

\section{DISEASES OF EARLY ADULTHOOD INTO MID-LIFE}

Borzekowski D, Schenk S, Wilson J, Peebles R. e-Ana and eMia: A content analysis of pro-eating disorder web sites. Am J Public Health. 2010;100(8):1526-34.

What Was Known? Eating disorders, such as anorexia (Ana) and bulimia (Mia), are highly prevalent. Adolescents who frequent pro-eating disorder websites are less satisfied with their bodies and practice disordered eating longer than peers not using these sites. ${ }^{6}$ Little is systematically known about the content of these sites.

What this Study Adds. This is the first large systematic review of pro-eating disorder websites. Investigators used Yahoo and Google search engines to find 180 active websites, forums, journals, or blogs focusing on pro-eating disorder information. Two reviewers independently coded the content using 64 variables organized into six themes (site logistics, site accessories, "thinspiration" materials, recovery, perceived themes, and perceived harm). Ninety-one percent of the websites were publicly accessible and $79 \%$ were interactive, wherein users could post content or use tools (e.g., diet calculators). Pro-anorexia content was provided on $84 \%$ of websites, pro-bulimia on $64 \%$, thinspiration images or prose to inspire weight loss on $85 \%$, and overt suggestions for engaging in eating-disordered behavior on $83 \%$. Only $38 \%$ of websites offered recovery advice or a link to such information. The 
investigators rated the websites on perceived harm using a 5point Likert scale, in which 83 sites were ranked medium harm (score 2 or 3 , content somewhat dangerous) and 39 sites were ranked high harm (score 4 or 5 , content could lead to immediate and life-threatening problems). Common themes on pro-eating disorder websites were control, success, perfection, solidarity, and a cult-like mentality of anorexia/ bulimia being a gift, not a lifestyle choice for "wannabe" dieters. Photographs of emaciated models and celebrities, creeds, and "Thin Commandments" 7 are examples of the content used to inspire and motivate disordered eating behaviors.

How Should I Change my Practice? Practitioners should be aware of the detrimental messages on pro-eating disorder websites. These sites are dynamic communities that often serve as venues for expression, encouragement, and support for disordered eating behaviors.

Giuliano A, Hunt K, Ballman K, et al. Axillary dissection vs. no axillary dissection in women with invasive breast cancer and sentinel node metastasis. JAMA. 2011;305(6):569-75.

What Was Known? Axillary lymph node dissection (ALND) has been the standard of care for breast cancer patients with sentinel lymph node (SLN) metastasis. ALND is associated with a high risk of complications ${ }^{8}$, and its effect on long-term survival has not been definitively demonstrated.

What this Study Adds. This multicenter, noninferiority trial randomized 891 women with clinically confirmed $\mathrm{T} 1$ or T2 invasive breast cancer and one or two tumor-involved SLNs to SLN dissection (SLND) alone or ALND. Adjuvant systemic chemotherapy was administered per the discretion of the treating physician; chemotherapy rates were similar for both groups (97\% SLND alone, 96\% ALND). After a median followup of 6.3 years, there were no differences in 5-year overall survival rates (92.5\% SLND alone, 91.8\% ALND) or diseasefree survival rates (83.9\% SLND alone, $82.2 \%$ ALND) between the groups. Rates of wound infections, axillary seromas, and paresthesias were significantly higher in the ALND than SLNDalone group $(70 \%$ versus $25 \%$, respectively, $P<0.001)$, as was lymphedema $(P<0.001)$.

How Should I Change my Practice? Although the follow-up period in this study was short, most axillary tumor recurrence presents at 1-2 years. Therefore, internists should feel comfortable reinforcing to patients that ALND does not improve the survival of patients with ductal carcinoma and positive SLNs, and results in more frequent complications such as wound infections and lymphedema.

Schnatz P, Marakovitz K, O'Sullivan D. The association of breast arterial calcification and coronary heart disease. Obstet Gynecol. 2011;117(2):233-41.

What Was Known? Coronary heart disease (CHD) is the leading cause of death among women. While radiographic studies have found an increased prevalence of intimal calcifications in vessels (e.g., coronary and aorta) among patients with $\mathrm{CHD},{ }^{9,10}$ and breast arterial calcifications (BAC) are common on mammograms ( $9 \%$ overall and up to $50 \%$ in women over age 65), the clinical significance of these calcifications is unknown.

What this Study Adds. This 5-year prospective cohort study enrolled 1,995 women from four outpatient radiology facilities. Surveys were administered at baseline and at years 2, 4, and 5. Mammograms were reviewed by a blinded radiologist to determine the presence of BAC. At baseline, the mean age was 56.3 years, 95\% were white, $61 \%$ post-menopausal, and $16.3 \%$ were BAC-positive. The BAC-positive group was older than the BAC-negative group (69 vs 54 years, $\mathrm{p}<0.001)$ ) and had a higher prevalence of most CHD risk factors (hypertension, hypercholesterolemia, diabetes, and postmenopausal). Over the 5-year study period, the prevalence of CHD was $20.8 \%$ in the BACpositive group compared to $5.4 \%$ in the BAC-negative group $(P<0.001)$. In the cohort without $\mathrm{CHD}$ at baseline, the BACpositive group was more likely to develop CHD $(6.3 \%$ vs $2.3 \%$ respectively, $P=0.003$ ). The presence of $\mathrm{BAC}$ was a better 5-year predictor of incident CHD than hypertension, hypercholesterolemia, or family history of CHD, independent of age and other confounders.

How Should I Change my Practice? The presence of BAC on mammography is likely a marker for CHD and should be routinely reported. Clinicians evaluating patients with BACpositive mammograms should consider factoring it into their decision making regarding CHD prevention.

\section{MANAGEMENT OF THE MENOPAUSAL WOMAN}

Freeman E, Guthrie K, Caan B, et al. Efficacy of escitalopram for hot flashes in healthy menopausal women: a randomized controlled trial. JAMA. 2011;305(3):267-74.

What was Known? Hormone replacement therapy is the most effective treatment for relieving menopausal vasomotor symptoms, but its use is limited by increased rates of stroke and venous thromboembolic disease. ${ }^{11}$ Non-hormonal therapies, including antidepressants and neuroleptics, reduce hot flashes by $40-84 \% .{ }^{12}$ Few studies have examined whether the effectiveness of non-hormonal therapies is influenced by race, menopausal status, or a personal history of anxiety or depression.

What this Study Adds Women $(\mathrm{n}=250)$ with moderately severe hot flashes were randomized to escitalopram $10 \mathrm{mg}$ daily or placebo for 8 weeks. Almost half of the study participants were African-American, and 14-23\% reported mild depression or anxiety at baseline. After 8 weeks of treatment, patients in the escitalopram group experienced 1.40 fewer hot flashes per day and a reduction in severity than those in the placebo group. Although there was a substantial placebo effect, more women in the escitalopram group experienced at least a 50\% reduction 
in hot flash frequency (55\% vs $36 \%, \mathrm{p}=0.009)$. Race, menopausal status, and a history of depression or anxiety did not modify the treatment effect, and adverse events were few. Patient satisfaction and desire to continue with treatment was higher with escitalopram than placebo (70\% vs $43 \%$, p $<0.001$, and $64 \%$ vs $42 \%, p=0.005$, respectively).

How Should I Change my Practice? Escitalopram may be a good treatment option for symptomatic women who want to avoid systemic hormone therapy, and will be effective even in those without anxiety or depression.

Renoux C, Dell'aniello S, Garbe E, Suissa S. Transdermal and oral hormone replacement therapy and the risk of stroke: a nested case-control study. BMJ. 2010;340:c2519.

What Was Known? Oral hormone therapy for relief of menopausal symptoms increases the risk for ischemic stroke. ${ }^{13}$ Transdermal hormone therapy, while equally efficacious, avoids the hepatic first-pass effect and is less likely than oral therapy to increase cardiovascular risk markers. ${ }^{14}$ To date, no studies have compared the effects of transdermal and oral hormone therapy on stroke risk.

What this Study Adds Using a large British medical record database and a nested case-control study design, the investigators examined the rates of stroke among older women who were exposed to hormone therapy. The route (oral vs transdermal) and dose (high vs low dose estrogen) of hormone therapy were compared among 15,710 cases and 59,958 controls. After adjustment for multiple cardiovascular risk factors, women who used transdermal estrogen or estrogen/progesterone hormone therapy had no increased risk of stroke compared with non-users (rate ratio 0.95, 95\% CI 0.75-1.20), although this was only true with doses of estrogen less than $50 \mu \mathrm{g}$. Conversely, treatment with oral estrogen significantly increased the risk of stroke by $35 \%$, an effect that was mitigated only slightly if oral estrogen was combined with progesterone (rate ratio 1.24 , 95\% CI 1.08 1.41). Stroke risk with oral hormone therapy did not vary significantly when stratified according to low or high estrogen doses (rate ratio 1.25 , 95\% CI $1.12-1.40$ vs 1.48 , 95\% CI 1.16 1.90, respectively). In a direct comparison, treatment with transdermal hormone therapy was associated with a lower risk of stroke than oral therapy (rate ratio $0.74,95 \%$ CI $0.58-0.95$ ).

How Should I Change my Practice? This study suggests that transdermal hormone therapy is safer than oral therapy. Although case control study designs have inherent biases, there is biological plausibility for these results based on prior studies. Providers should consider selecting transdermal routes of hormone administration to minimize the risks associated with systemic therapy.

Chlebowski R, Anderson G, Gass M, et al. Estrogen plus progestin and breast cancer incidence and mortality in postmenopausal women. JAMA. 2010;304(15):1684-92.
What was Known? In the Women's Health Initiative (WHI) placebo-controlled trial, women who were treated with combined estrogen and progestin (E/P) therapy had an increased risk of invasive breast cancer. Moreover, these breast cancers tended to be larger and at a more advanced stage at the time of detection. ${ }^{15}$ Although the risk of breast cancer declined significantly after discontinuation of $\mathrm{E} / \mathrm{P}{ }^{16}$, the long-term effects of $\mathrm{E} / \mathrm{P}$ on breast cancer incidence, characteristics at diagnosis, and breast cancer mortality are unclear.

What this Study Adds Although the WHI was stopped early in 2002, all subjects were followed for an additional 3 years, until the original trial completion date ("post-intervention phase"). Eighty-three percent of women consented to participate in the "extension phase," and data regarding breast cancer incidence and mortality were collected prospectively until 2009. In total, after a mean follow-up of 11.0 years, 678 cases of breast cancer were identified. Treatment with $\mathrm{E} / \mathrm{P}$, as compared to placebo, was associated with a significantly increased incidence of invasive breast cancer (HR 1.25, 95\% CI 1.07-1.46). Women in the treatment group, as compared to those receiving placebo, were more likely to have positive lymph nodes at the time of diagnosis and were more likely to die from breast cancer ( 25 deaths vs 12 deaths, HR 1.96, 95\% CI 1.00-4.04). Overall mortality after a diagnosis of breast cancer was higher in the $\mathrm{E} / \mathrm{P}$ group than in the placebo group (51 deaths vs 31 deaths, HR 1.57, 95\% CI 1.01-2.48).

How Should I Change my Practice? Treatment with E/P increases the incidence of invasive breast cancer, and the risk persists after discontinuation of therapy. Moreover, E/P increased breast cancer mortality and overall mortality, although the number of deaths in both groups was relatively small. In light of these new data, practitioners should continue to carefully weigh the risks and benefits of $\mathrm{E} / \mathrm{P}$ therapy and counsel patients appropriately.

\section{OSTEOPOROSIS AND BONE HEALTH}

Bolland M, Avenell A, Baron J, et al. Effect of calcium supplements on risk of myocardial infarction and cardiovascular events: meta-analysis. BMJ. 2010;341(c3691).

What was Known? While widely recommended, calcium has been shown to be necessary but not sufficient for reducing osteoporosis risk. ${ }^{17}$ A previous randomized controlled trial in healthy older women with prespecified CVD outcomes showed possible increases in MI and cardiovascular events in women who took calcium. ${ }^{18}$

What this Study Adds This meta-analysis included 15 RCTs that had at least 100 participants aged 40 and older and had a study duration of at least 1 year. Among a total of 15 eligible 
trials, 5 provided patient level data on 8,151 participants and 11 provided trial level data on 11,921 participants. All included studies used calcium alone, without vitamin D supplement. In the 5 studies with patient level data, 143 people on calcium had a myocardial infarction (MI) compared with 111 allocated to placebo (hazard ratio $1.3195 \%$ CI $1.02,1.67$ ). In the metaanalysis of trial level data, 166 on calcium had an MI vs. 130 on placebo, pooled RR 1.27, 95\% CI 1.01-1.59. Nonsignificant increases were also seen in stroke incidence, death, and the composite endpoint of myocardial infarction, stroke, or sudden death. The number needed to treat with calcium for 5 years to cause one incident event was 69 for MI, 100 for stroke, 61 for MI, stroke or sudden death, and 77 for death.

How Should I Change my Practice? Calcium supplements without co-administered vitamin D should be limited as they are associated with a small increased risk of myocardial infarction and other vascular disease. It is unclear whether vitamin $\mathrm{D}$ ameliorates this effect, though vitamin $\mathrm{D}$ deficiency is associated with increased CHD. Although calcium supplements have been shown to modestly increase BMD, they have only a modest protective effective effect against fracture. ${ }^{17}$

Sanders K, Stuart A, Williamson E, Simpson J, Kotowicz M, Young D, et al. Annual high-dose oral vitamin D and falls and fractures in older women: a randomized controlled trial. JAMA. 2010;303(18):1815-22.

What Was Known? While vitamin D affects bone health, prior studies of the effects of cholecalciferol (vitamin D) on falls and fractures have been inconsistent. ${ }^{17,19-29}$ Although $25-\mathrm{OH}$ vitamin D "deficiency" is frequently treated, the impact on fracture outcomes is unclear.

What this Study Adds This single-center double-blind study randomized 2,256 community-dwelling women aged $70+$ to a single annual dose of cholecalciferol (500,000 IU) or placebo for 3-5 years. Falls and fractures were measured by monthly telephone interviews and confirmed radiographically in a substudy. One hundred fifty-five women on vitamin D had 171 fractures and 125 women on placebo had 135 fractures, (RR 1.26; $95 \%$ CI $1.00,1.59$ ). The relative risk for falling was also increased in the vitamin D group $(1.31,95 \%$ CI 1.12-1.54) in the first 3 months after the annual dose, but was not significant in the subsequent 9 months.

How Should I Change my Practice? High dose annual supplementation of vitamin D is not recommended for fall and fracture prevention. Whether more frequent or lower doses of vitamin D may prevent falls or fractures remains unknown. Based on the results of new studies, the Institute of Medicine has recently updated their guidelines for vitamin $\mathrm{D}$ intake. The new guidelines for vitamin D are 600 IU (daily) for women aged 9-70, and 800 IU for women over age 70 with an upper recommended limit of 4,000 IU per day. In addition, the target $25-\mathrm{OH}$ vitamin D levels have been revised. A serum $25-\mathrm{OH}$ vitamin D level of $20 \mathrm{ng} / \mathrm{ml}$ is now the goal.

Black D, Kelly M, Genant H, et al. Bisphosphonates and fractures of the subtrochanteric or diaphyseal femur. NEJM. 2010;362(19):1761-71.

What Was Known? Several case series have reported an increased risk of atypical femoral shaft fractures (fractures of the subtrochanteric or diaphyseal femur) with alendronate. ${ }^{30-42}$ However, it has not previously been possible to estimate population prevalence or identify risk factors.

What this Study Adds Study investigators performed secondary analyses of three large randomized trials of bisphosphonates. These trials included the Fracture Intervention Trial (FIT), the FIT Long-Term Extension (FLEX) trial and the Health Outcomes and Reduced Incidence with Zolendronic Acid Once Yearly (HORIZON) Pivotal Fracture Trial (PFT). They had detailed records of fractures and radiographs to ascertain exact fracture locations and typical or atypical characteristics of the fracture. There were a total of 284 fractures among 14,195 women. Of the 284 fractures, 12 fractures in 10 patients were subtrochanteric or diaphyseal fractures, resulting in combined rate of 2.3 per 10,000 patient years. Compared with placebo, the relative hazard for alendronate in FIT was 1.03 (95\% CI, 0.06, 16.46); the relative hazard for zolendronic acid use in HORIZON-PFT was $1.5(0.25,9.00)$, and the relative hazard for continued alendronate use in FLEX was $1.33(0.12,14.67)$. Fracture of the subtrochanteric or diaphyseal femur was very rare even in women on bisphosphonates for up to 10 years. Although all the point estimates showed an increased risk, the confidence intervals were wide because of the small number of events.

How Should I Change my Practice? Even if there is a small risk of atypical fracture associated with bisphosphonates, this must be weighed against the population benefits associated with the overall reduction in hip fractures among women with osteoporosis.

Acknowledgements: This work was presented at the 2011 Annual Meeting of the Society of General Internal Medicine in Phoenix, Arizona.

Conflict of Interest: None disclosed.

Corresponding Author: Judith M. E. Walsh, MD, MPH; UCSF Division of General Internal Medicine, UCSF Women's Health Clinical Research Center, University of California, 1635 Divisadero Suite 600, San Francisco, CA 94115, USA (e-mail: Judith.Walsh@ucsf.edu).

\section{REFERENCES}

1. Rybo G. Tranexamic Acid Therapy—effective treatment in heavy menstrual bleeding. Clinical update on safety. Therapeutic Advances. 1991;4:1-8.

2. Milsom I, Andersson K, Andersch B, Rybo G. A comparison of flurbiprofen, tranexamic acid, and a levonorgestrel-releasing intrauterine contraceptive device in the treatment of idiopathic menorrhagia. Am J Obstet Gynecol. 1991;164(3):879-83. 
3. Mosher WD, Jones J. Use of contraception in the United States: 19822008. Vital and Health Statistics. 2010;23(29).

4. Foster D, Parvataneni R, de Bocanegra H, Lewis C, Bradsberry M, Darney P. Number of oral contraceptive pill packages dispensed, method continuation, and costs. Obstet Gynecol. 2006;108(5):1107-14.

5. Jones R, Kooistra $\mathbf{K}$. Abortion in the United States: Incidence and Access to Services, 2005. Perspect Sex Repod Health. 2008;40 (1):6-16.

6. Harper K, Sperry $\mathbf{S}$, Thompson $\mathbf{J}$. Viewership of pro-eating disorder websites: association with body image and eating disturbances. Int $\mathrm{J}$ Eat Disord. 2008;41(1):92-5.

7. Costin C. Your Dieting Daughter: Is She Dying for Attention?: Routledge; New York, New York 1996.

8. Lucci A, McCall L, Beitsch P, American College of Surgeons Oncology Group, et al. Surgical complications associated with sentinel lymph node dissection (SLND) plus axillary lymph node dissection compared with SLND alone in the American College of Surgeons Oncology Group Trial Z0011. J Clin Oncol. 2007;25(24):3657-63.

9. Moore E, Greenberg R, Merrick S, Miller S, McLoud T, Shepart J. Significance of incidental detection on CT scans. Radiology. 1989;172:711-6.

10. Witteman J, Kok F, van Saase J, Valkenburg H. Aortic calcification as a predictor of cardiovascular mortality. Lancet. 1986;2:1120-1122.

11. Rossouw J, Anderson G, Prentice R, et al. Risks and benefits of estrogen plus progestin in healthy postmenopausal women: principal results From the Women's Health Initiative randomized controlled trial. JAMA. 2002;288(3):321-33.

12. Loprinzi C, Sloan J, Stearns V, et al. Newer antidepressants and gabapentin for hot flashes: an individual patient pooled analysis. $\mathrm{J}$ Clin Oncol. 2009;271(17):2831-7.

13. Bath P, Gray L. Association between hormone replacement therapy and subsequent stroke: a meta-analysis. BMJ. 2005;330(7487):342.

14. Hemelaar M, van der Mooren M, Rad M, Kluft C, Kenemans P. Effects of non-oral postmenopausal hormone therapy on markers of cardiovascular risk: a systematic review. Fertil Steril. 2008;90(3):642-72.

15. Chlebowski R, Hendrix S, Langer R, et al. Influence of estrogen plus progestin on breast cancer and mammography in healthy postmenopausal women: the Women's Health Initiative Randomized Trial. JAMA. 2003;289(24):3243-53.

16. Chlebowski R, Kuller L, Prentice R, et al. Breast cancer after use of estrogen plus progestin in postmenopausal women. NEJM. 2009;360 (6):573-87.

17. Jackson R, et al. Calcium plus vitamin D supplementation and the risk of fractures. NEJM. 2006;354(7):669-83.

18. Bolland $\mathbf{M}$, Barber $\mathbf{P}$, Doughty $\mathbf{R}$, et al. Vascular events in healthy older women receiving calcium supplementation: randomised controlled trial. BMJ. 2008;336:262-6.

19. Grant A, Anderson F, Avenell A, et al. Oral vitamin D3 and calcium for secondary prevention of low-trauma fractures in elderly people (Randomised Evaluation of Calcium or Vitamin D, RECORD). Lancet. 2005;365 (9471):1621-8.

20. Trivedi D, Doll R, Khaw K. Effect of four monthly oral vitamin D supplementation on fractures and mortality in men and women living in the community: randomised double blind controlled trial. BMJ. 2003;326(7387):469-75.

21. Chapuy M, Arlot M, Delmas P, Meunier P. Effect of calcium and cholecalciferol treatment for three years on hip fractures in elderly women. BMJ. 1994;308(6936):1081-2.

22. Chapuy M, Arlot M, Duboeuf F, et al. Vitamin $D_{3}$ and calcium to prevent hip fractures in elderly women. NEJM. 1992;327(23):163742.

23. Porthouse J, Cockayne $\mathbf{S}$, King $\mathbf{C}$, et al. Randomised controlled trial of calcium and supplementation with cholecalciferol (vitamin $\mathrm{D}_{3}$ ) for prevention of fractures in primary care. BMJ. 2005;330(7498): 1003.
24. Heikinheimo $\mathbf{R}$, Inkovaara $\mathbf{J}$, Harju $\mathbf{E}$, et al. Annual injection of vitamin D and fractures of aged bones. Calcif Tissue Int. 1992;51(2):10510.

25. Smith H, Anderson F, Raphael H, Maslin P, Crozier D, Cooper C. Effect of annual intramuscular vitamin D on fracture risk in elderly men and women: a population-based, randomized, double-blind, placebocontrolled trial. Rheumatology (Oxford). 2007;46(12):1852-7.

26. Larsen E, Mosekilde L, Foldspang A. Vitamin D and calcium supplementation prevents osteoporotic fractures in elderly community dwelling residents: a pragmatic population-based 3-year intervention study. J Bone Miner Res. 2004;19(3):370-8.

27. Dawson-Hughes B, Harris S, Krall E, Dallal G. Effect of calcium and vitamin D supplementation on bone density in men and women 65 years of age or older. NEJM. 1997;337(10):670-6.

28. Lyons R, Johansen A, Brophy S, et al. Preventing fractures among older people living in institutional care: a pragmatic randomised double blind placebo controlled trial of vitamin D supplementation. Osteoporos Int. 2007;18(6):811-8.

29. Prince R, Austin N, Devine A, Dick I, Bruce D, Zhu K. Effects of ergocalciferol added to calcium on the risk of falls in elderly high-risk women. Arch Intern Med. 2007;168(1):103-8.

30. Ing-Lorenzini K, Desmeules J, Plachta O, Suva D, Dayer P, Peter R. Low-energy femoral fractures associated with the long-term use of bisphosphonates: a case series from a Swiss university hospital. Drug Saf. 2009;32:775-85.

31. Kwek E, Goh S, Koh J, Png M, Howe T. An emerging pattern of subtrochanteric stress fractures: a long-term complication of alendronate therapy? Injury. 2008;39:224-31.

32. Capeci C, Tejwani N. Bilateral low-energy simultaneous or sequential femoral fractures in patients on long-term alendronate therapy. $\mathrm{J}$ Bone Joint Surg Am. 2009;91:2556-61.

33. Odvina C, Levy S, Rao S, Zerwekh J, Sudhaker Rao D. Unusual midshaft fractures during long term bisphosphonate therapy. Clin Endocrinol (Oxf). 2009 March 19;(Epub ahead of print).

34. Somford M, Draijer F, Thomassen B, Chavassieux P, Boivin G Papapoulos S. Bilateral fractures of the femur diaphysis in a patient with rheumatoid arthritis on long-term treatment with alendronate: clues to the mechanism of increased bone fragility. J Bone Miner Res. 2009;24:1736-40.

35. Armamento-Villareal R, Napoli N, Diemer K, et al. Bone turnover in bone biopsies of patients with low-energy cortical fractures receiving bisphosphonates. Calcif Tissue Int. 2009;85:37-44.

36. Cheung $\mathbf{R}$, Leung $\mathbf{K}$, Lee $\mathbf{K}$, Chow $\mathbf{T}$. Sequential non-traumatic femoral shaft fractures in a patient on long-term alendronate. Hong Kong Med J. 2007; 13:485-9.

37. Armamento-Villareal R, Napoli N, Panwar V, Novack D. Suppressed bone turnover during alendronate therapy for high-turnover osteoporosis. NEJM. 2006;355:2048-50.

38. Goh S, Yang K, Koh J, et al. Subtrochanteric insufficiency fractures in patients on alendronate therapy: a caution. J Bone Joint Surg Br. 207;89:349-53.

39. Odvina C, Zerwekh J, Rao D, Maalouf N, Gottschalk F, Pak C. Severely suppressed bone turnover: a potential complication of alendronate therapy. J Clin Endocrinol Metab. 2005;90:1294-301.

40. Visekruna M, Wilson D, McKiernan F. Severely suppressed bone turnover and atypical skeletal fragility. J Clin Endocrinol Metab. 2008;93:2948-52.

41. Neviaser A, Lane J, Lenart B, Edobor-Osula F, Lorich D. Low-energy femoral shaft fractures associated with alendronate use. J Orthop Trauma. 2008;22:346-50.

42. Lenart B, Lorich D, Lane J. Atypical fractures of the femoral diaphysis in postmenopausal women taking alendronate. NEJM. 2008;358:13046. 